\title{
Comunicação visual no Transporte Público - estudo de caso no município de Campinas - SP
}

\author{
Henrique de Siqueira Guida (IC), Maria Teresa Françoso (PQ)
}

\begin{abstract}
Resumo
Esta pesquisa teve como principais objetivos estudar os sistemas de comunicação visual e a criação de mapas temáticos simplificados de itinerários de transporte público, com enfoque à confecção de diagramas baseado na união entre elementos do design gráfico e das informações do transporte público. Realizou-se um estudo de caso do município de Campinas a partir do mapeamento dos itinerários do transporte público da cidade, utilizando um Sistema de Informação Geográfica. Com base nesse mapeamento, elaborou-se a linearização/diagramação dos itinerários em operação vinculados a 4 terminais (Vila União, do Campo Grande, Itajaí e Iguatemi), com objetivo de facilitar a interpretação da rota desempenhada pelo ônibus na cidade. A partir disto pôde-se mapear o transporte público de Campinas utilizando o software Maplnfo Proviewer, incluindo pontos de referência. Como resultado, foi elaborado um modelo de linearização, utilizando o software AutoCAD, que servirá para orientar os usuários de forma clara e precisa na escolha dos itinerários e pontos de parada, buscando facilitar a realização das atividades cotidianas dos moradores.
\end{abstract}

Palavras Chave: Comunicação visual, transporte público, linearização de itinerários de transportes

\section{Introdução}

É de vital importância que uma cidade, a fim de desenvolver seu transporte público, planeje meios para que este possa alcançar a população em geral. Para que isto possa ser realizado, a comunicação visual possui um papel imprescindível uma vez que, a partir desta, as informações sobre o sistema de transporte podem ser transmitidas aos usuários. Uma maneira de expor tais dados é por via de mapas simplificados que linearizam os trajetos executados (mapas tubulares), aos quais podem estar associados elementos relativos aos itinerários, alternativas de integração do transporte e pontos de interesse.

\section{Resultados e Discussão}

O resultado desta pesquisa foi o aprofundamento no conhecimento da elaboração de mapas simplificados utilizados para comunicação visual do transporte público (mapas tubulares). A partir disso, elaboram-se modelos de linearização dos itinerários de 4 terminais de ônibus do município de Campinas (Vila União, do Campo Grande, Itajaí e Iguatemi), dando continuidade ao trabalho realizado por Agueda (2013), confeccionando quatro mapas temáticos (mapas tubulares). Para isto, utilizando uma base cartográfica do município de Campinas cedida pela Empresa Municipal de Desenvolvimento de Campinas Emdec, traçou-se os itinerários que alimentam os 4 terminais a partir das informações disponíveis no site da Emdec. Em seguida, verificou-se a localizados dos pontos de interesse relativos às linhas envolvidas para servirem como referência aos usuários. Com o auxílio dos softwares AutoCAD e Maplnfo Proviewer, pôde-se, então, produzir os mapas simplificados, aliando os trajetos aos determinados pontos. Vale ressaltar que, para tanto, foram seguidas algumas convenções determinadas no âmbito da confecção dos mapas, relacionadas à geometria, à geografia, ao design e à nomenclatura (CARDIN 2005 e FERRAZ; TORRES 2004).

\section{Conclusões}

A partir da elaboração dos mapas temáticos e da revisão bibliográfica, nota-se que as cidades brasileiras, em especial Campinas, carecem de infraestrutura relativa ao transporte público urbano. Logo, uma comunicação visual efetiva é um dos passos para a melhoria deste sistema. Portanto, cabe salientar que os mapas linearizados contribuem para o aperfeiçoamento e desenvolvimento desta área, possibilitando, então, aos usuários o acesso à informação.

\section{Agradecimentos}

Conselho Nacional de Desenvolvimento Científico e Tecnológico - CNPq pela concessão de bolsa de Iniciação Científica vinculada ao Programa Institucional de Bolsas de Iniciação Científica PIBIC.

\footnotetext{
AGUEDA, B. F. Sistemas de comunicação visual com informação ao usuário de transporte. Trabalho Final (Graduação) - Curso de Engenharia Civil, Unicamp, Campinas, 26 p., 2013

CARDIN, Pablo. Simplificações em tipografia. Dissertação (Mestrado em Design Gráfico) - Centro Universitário Belas Artes. São Paulo, 2005.

${ }^{3}$ FERRAZ, A.C.P.; TORRES, I.G.E. Transporte público urbano. São Carlos, RiMa, 2004. 428p.
} 